\title{
Risk and Responsibility in the Medical Pharmaceutical Practice
}

\author{
Stelian Paris \\ Prof. Assoc. Dr. "Ovidius" University of Constanta, Faculty of Pharmacy \\ Rodica Sirbu \\ "Ovidius" University of Constanta, Faculty of Pharmacy \\ Cristina-Luiza Erimia \\ "Ovidius" University of Constanta, Faculty of Pharmacy
}

\begin{abstract}
The authors make an analysis of a highly important problem, that is the responsibility in the medicalpharmaceutical practice starting from the fact that a young person who applies for a Medicine or Pharmacy university, gains an idea - no matter how small - of the multitude and the scale of the responsibilities that he/she is going to have during the course of the medical-pharmaceutical activity. We are constantly responsible but the responsibility of those in the medical-pharmaceutical field is permanent and multiple, on a number of levels, being recognized as follows: professional responsibility (deontological) towards the patient, juridical responsibility (civil, criminal), administrative responsibility (the respect of the laws), economic responsibility (spending) and social responsibility.
\end{abstract}

Keywords: social responsibility, efficiency, risk in the medical practice, medical-pharmaceutical activity

\section{INTRODUCTION}

It is very difficult to imagine that a young man or woman, who aspires to go to the faculty of medicine, forms an idea - as small as it can be - about the multitude and dimensions of the responsibilities that is about to undertake in the medical practice. Or maybe if a physician with experience enumerated and underlined them some of the candidates would not go any further.

Indeed, all those who have completely dedicated their life to medicine and seriously focused on medical practice, certainly remember the heavy task of responsibilities in their medical life. We are responsible all the time: the physician's responsibility is constant, daily and multiple on several aspects.

So, we observe the following responsibilities:

- Professional (deontological) responsibility towards the patient, which must be completely understood and undertaken as a primary primordial responsibility;

- Legal (civil, criminal liability) responsibility that must always be considered but without focusing on the physician's spirit in order not to influence the total fulfillment of the other responsibility, the professional ${ }^{1}$ one;

- Administrative responsibility of the medical costs ordered by the physician, which nowadays has become a huge responsibility towards the community through the high cost of medical acts; 
- Social responsibility: "medicine is not only a profession but also a high social activity" [1].

All these responsibilities, so important and diverse, make the physician's life very restless and agitated as Andre Maurois said: "heroic, difficult, tormented and sometimes sublime".

\section{THE DIFFICULT ROLE OF THE PHYSICIAN}

One of the relevant sources of this issue is the contradiction created by the double responsibility of the physician: towards the patient and towards the community [2]. The community makes the physicians responsible of the high cost of medical assistance, public health programs and warns about the fact that the medical costs rhythm grows faster than the national income (which is very true). On the other hand, the patients - more and more well informed on medical aspects demand more diagnostic procedures, more drugs, more health care and more hospitalization. This is how some countries reach a sort of "medical inflation" [2].

But can we think about the fight against disease only in terms of profitability? Which are the limits that can be reached in order to respect the human value of the medical acts and - at the same time - their efficiency? (Efficiency = the relation between cost and benefits achieved by the people). When we are asked to reduce the hospitalization period of the patient, who shall defend the physician against their claims, taking into account the possible risks of an unexpected development of the disease or the omission of carrying out some analyses or their repetition? he fear of such claims and legal consequences make some physicians to abuse some scanning, often expensive and superfluous, increasing more and unreasonably the cost of medical assistance. In a justified way there are suggested the following: controlled studies of the sanitary sector (studies that compare different hospitals or groups of population), outpatient medical services (much cheaper than hospital medicine which costs up to $60 \%$ of the health budget) and more prevention actions.

Objectively speaking, the medical progress to the man's wellbeing must go hand in hand with a profitable economy and the physician has the difficult role to keep the balance between these two conditions.

\section{RISK IN THE MEDICAL PRACTICE}

Medicine is not only a science but also an art and the medical practice is an art that entails appropriate knowledge and application of scientific data. The physician undertakes the task to competently and devotedly take care of the patient but he cannot foresee everything nor provide absolute guarantee of healing. The medical practice is full of unforeseen and risks. Recently a medical personality from England made the following question: "Can medical practice be exempted from the risk?"; the same author answers: "No, the risks are inherent in any subject where uncertainties are frequent and decisions are made on probabilities ${ }^{1 "}$.

As physicians we run risks all the time. We risk when we give a diagnostic, apparently logical (but not always what is logic happens in medicine), when we take a therapeutic decision or when we prescribe a drug. There is no drug without side effect. Someone once said that if we admit that surgeons are descendants of the Middle Ages barbers than pharmacologists are also descendants of the Borgia family (famous through their refinement in poisons). And we have to prescribe drugs which often have the therapeutic limit close to the toxic limit, or we have to expose ourselves to the most unexpected reactions of sensitization.

Of course that there is also an estimated risk, through which in modern medicine we evaluate the development of a medical act, its use (therapeutic value or diagnostic) towards the risk of side effects. When the positive value dominates the physician can undertake the risk of application but only after a serious reflection. An example is carrying out a blood transfusion when this is essential for the patient's life or health. In this case, we undertake the risk of causing (in $5-10 \%$ of the cases) the later occurrence of a post transfusion hepatitis, determined by one of the hepatitis viruses which exist in the donor's blood without being detected through the current technical possibilities (and therefore not eliminated). The estimated risk is taken into account also in the case of some difficult but necessary surgeries. In these cases, the surgeon has to obtain the informed consent of the patient or - if this is not possible - of the family. It is justified and ethical that under such circumstance the risks be shared with the patient. In this purpose, it is useful for the physician to ask for the 
patient's signature. But in certain unforeseen or emergency situations or during a surgery the surgeon must decide by himself according to his conscience and competence. This raises the following question: is really indicated to present the patient all the possible risks of such a medical act? We are in a field with great interpretative and orientation issues. But it is not possible or desirable to expose all the risks of a medical procedure to the patient [3].

\section{RESULTS AND DISCUSSIONS}

\section{DEFENSIVE MEDICINE: CONSEQUENCE OF THE PHYSICIAN-PATIENT CONFIDENCE CRISIS}

In some western countries, especially in North America the patient information on the risk of the medical act is carried out without any omissions in order to prevent any type of claims from the patient. Therefore, a physician-patient confidence crisis developed and a degeneration of the medical practice into the so-called defensive medicine, meaning the medicine for the defense of the physician. The causes are the multiple claims and legal actions against the physicians for malpractice, from unsatisfied patients. In these actions also contribute lawyers that are specialized in trials against physicians, by searching and exploiting the smallest dissatisfactions of the patients.

Many ask themselves whether the classical physician-patient relationship was annulled, which is not excluded and the famous physician-patient colloquium be transformed into a "dialogue of the deaf".

Actually the physicians from these countries, especially the ones exposed to the medical risk (surgeons, anesthetist, orthopedists, and gynecologists) defend themselves from these trials in different ways:

- By prescribing analyses with $50-60 \%$ more than the usual in order to be protected against the patients' claims, increasing the cost of the medical services;

- $\quad$ By informing the patients on all the possible risks, especially the surgical ones, until obtaining the so-called patient faint or their renunciation of the suggested surgery;

- $\quad$ By physicians insurance against risks of claims from patients, in order to be protected against lawsuits with them. The quantity of such insurances has reached in the U.S.A. the value of 2 billion dollars, a significant number that shows how much it can cost the physicians the medical responsibility, which is so deteriorated by the lost of confidence in the physician-patient relationship.

"How difficult is to heal people's diseases?"(Quando difficile est curare morbes hominum) said Celsus some centuries ago. But today, taking into account the burden of so many risks of modern medical practice.

\section{DEONTOLOGY OF THE MEDICAL RISK}

There is a deontology of the medical risk which focuses on several types of risks [4].

Predictable risks (conscious) are those risks that may pass through an anticipated assessment and are admitted after a calculation that justifies its acceptance for the patient's interest (assessed risk).

Who has the benefit must run also the risks [5].

Unpredictable risks are unexpected, inappropriate and uncontrollable that result from a necessary situation (emergency, force majeure case). In these circumstances the unpredictable character does not undertake the physician's responsibility.

Nevertheless, it is the physician's duty and the desired medical progress for all the medical risks to become more and more reduced for the patient. There are also illegitimate, unjustified risks that refer to some lacks of the physician.

\section{RISKS THAT REFERS TO THE PHYSICIAN}

This type of risks refers to the physician, their qualification, work and behavior. Therefore, some physicians create themselves risks by incompetence or unconsciousness (sancta simplicitas!), negligence or fraud. All these fit in the socalled malpractice, in the Anglo-Saxon language, meaning incompetent, fraudulent practice that incurs sanctions (administrative or criminal) from the College of Physicians. 
Such deviations and serious faults affect the reputation and respect of the medical profession, with its huge responsibilities, generating severe criticism and appreciations, even since the ancient times, which some malicious spirits tried to generalize them to all the medical staff. In ancient times Pliny the Elder (first century of our era), with regard to the medicine from those times, said: "the physicians gain knowledge from the dangers that we go through, making experiences with the price of our life. Only a physician can commit homicide being protected by a complete impunity". Of course that such statement represents a great inaccurateness taking into account that the Hippocratic deontology - the principle of medical practice in those times - completely excluded such aspects of the medical practice and established behavior rules of high humanity, according to which the current medical deontology is also inspired.

Besides this necessary rectification, we must not forget to seriously analyze the deviations from the medical ethics of some colleagues, starting with the smallest deviations from the medical subject until the serious deviations, in order to prevent them (the ideal solution) or appropriately sanction them. During a symposium on medical subject held in 1979 in New-York, three types of physicians were analyzed, with deviations in the medical field [5]:

- Physicians with deviations from the moral behavior, unscrupulous that commit illegal medical acts or professional negligence, starting from the lack of interest in the patient until serious negligence;

- Physicians that are not capable of a responsible activity due to psychological diseases (mental illness) or drug addiction (alcoholism, etc.);

- Incompetent physicians that are situated under the standard of current knowledge, conscious or unconscious of their lack of knowledge and their lack of progress in the modern medicine development. These are those physicians that do not read any medical books or magazines, that avoid medical training courses or scientific societies meetings. Any physician that does not study constantly becomes: "a possible wrongdoer" [6].

All these attitudes represent serious risks for the patients, for the medical practice, which do not entail anymore the peculiarities of the medical practice but individual entities, physicians with such deviations that form a minority in the medical staff.

Such situations fit into the legal liabilities of the physician (civil and criminal), classified in different categories:

professional fault by negligence, professional fault by imprudence, professional fault by incompetence, etc, as they are presented in the specialized books [7], [8], [9].

\section{RISKS THAT REFERS TO THE PHARMACIST}

In the Code of Medical Deontology, the pharmacist has their own responsibilities which do not avoid, generally, the principles of the medical deontology [10]. The pharmacist's activity has the same purpose as the physician's activity so that, even if the moral work principles are common, they shall be customized according to the profession, stating that the physician-pharmacist deontological relationships must not be understood as subordination relationships but collaboration that serves a single purpose - the one to ensure a country's health [7].

The pharmacist has the obligation to ensure, in time, the assistance with drugs for the pharmaceutical network, patients and population in need of them, at the appropriate technical and scientific level [10].

The pharmacist must provide priority in the preparation and dispense of drugs from the emergency prescriptions. In special cases, the pharmacist has the obligation to respond to the emergency demands also outside their working hours. The pharmacist, in the limit of their knowledge, provides emergency aid to patients in cases when they cannot benefit from an immediate health care from a physician; the pharmacist shall guide towards the competent medical institution and shall inform the physician regarding the measures taken based on their own initiative. The pharmacist must competently proceed in solving technical issues of the drugs preparation in order to avoid incompatible reactions. The pharmacist must carry out medical prescriptions and assist people with drugs in an equal manner for any patient, except for emergency medical prescriptions, cases when priority is provided for the execution and dispense.

The pharmacist must apply unitary methods for the drugs preparation in order to ensure uniformity of execution and presentation; the purpose is to prevent doubts or suspicions from the patient regarding the drug's quality (equal shapes and sizes, uniformity in aspect, color, taste, smell, etc.). The pharmacist must avoid any expression of doubt and mistrust in the presence of the patient, regarding their treating physician or medical prescriptions. 
In the case when the pharmacist observes an incomplete or wrong formula in the medical prescription or when an ingredient must be replaced, they will contact the physician that prescribed the prescription in order to agree on solving the case. If the physician cannot be contacted and the drug's administration cannot be delayed, the pharmacist shall make the necessary change on their own responsibility and shall write on the prescription the adjustment, subsequently informing the physician on the changes.

The pharmacist is forbidden to make recommendations of drugs or any other therapeutic methods, the exception being only for hygienic products. The pharmacist must send the patients to the physician in order to obtain the necessary indication.

The two collaborators, the physician and the pharmacist must prevent polypragmasy and understand the psychology of the patient and/or of the groups that abusively consume drugs; they have to carry out systematic and constant prevention actions that are based on deontological behavior principles [7].

The physician and the pharmacist shall have a behavior based on collaboration, esteem and support towards the colleagues and other staff. It is forbidden to blame or denigrate colleagues through negative appreciations on their medical qualification or activity in front of the patients, family members or legal representatives, medical staff; it is also forbidden any expression or act that endangers the confidence in the physician or pharmacist or their professional activity. The necessary criticism shall be based on objective proof in an organized framework in order to have a positive effect [11].

The physicians and pharmacist have the obligation to permanently guide and control the subordinated staff's activity which shall be carried out according to principles, consistency and precision. The medical and pharmaceutical scientific activity must be based on moral's principles and respect of the human being. It is forbidden to cause artificial illness on healthy people or intentionally maintain a state of illness for the purpose of scientific researches [12].

\section{PREVENTIVE SOLUTIONS AND CURES}

What is to be done for reducing the risk in medical practice, both the medicine risk and the risk that derives from the deficient activities of a medical minority?

First of all, the most important ones are the preventive solutions on the educational plan starting from graduate level and going through post-graduate level by medical media, books, meetings, control and prevention actions on administrative and deontological plan (through the College of Physicians).

It is necessary to imprint the concept of continuous professional medical training which constitutes a moral obligation and the incompetent physician has not only a moral fault but also a legal fault.

It is useful to analyze also the new ethical issues brought by modern medicine progress (prenatal genetic diagnostic and genetic surgery, prolonged resuscitation, etc.) and the ethical solutions that are foreseen.

Minimum risk diagnosis techniques must be used.

New drugs must not be used without knowing their risks and without obtaining the informed consent of the patient for any special treatment.

A peer review must be carried out any time the patients' situation requires it.

The social and economic responsibility of the contemporary physician must be known.

Moreover, the ethical rules of the scientific research in clinical medicine must be known and applied.

On the other hand there is the "identification of the black sheep" of medicine and their sanctioning according to the socialist medical ethics and the current legislation on the medical responsibility.

\section{CONCLUSIONS}




\section{REDUCING THE MEDICAL - PHARMACEUTICAL RISK BY CONTINUOUS PROFESSIONAL TRAINING}

- We could not end this incursion in the medical practice risk issue and responsibilities without emphasizing the need of continuous professional training which we consider not only an important solution for reducing the medical practice risk but also an essential moral obligation of the physician and pharmacist [13].

- The desire for training must be present at each physician or pharmacist in order to deserve their title. Therefore, we must always be unpleased with ourselves, with our every day work, our reading or our knowledge regarding the patients and our tasks, reflecting upon the daily activities and accuracy that we have completed.

- Only a vast experience, a life lived between the suffering and symptoms of the patients from the hospital and in the core of the medical social issues of the field, will allow us to gain that complex value that characterizes the physician with clinical experience and large perspectives, who is at the same time clinician and epidemiologist.

- At the clinical experience must be added new daily reading in order to maintain high professional competence and to reduce at minimum the risk for the patient in medical practice. Even the success of using computers in the clinic depends on the accuracy of the data collected by the clinician, which are introduced in the computer ${ }^{1}$. In the opposite situation, on the contrary: "garbage in, garbage out". The physician's professional quality matters as well as the accuracy of the collected data and the correctly used terminology.

- In reducing the medical risk is also important the professional quality of the sanitary staff. Therefore we agree with the above quoted opinion ${ }^{2}$ that says "a very good experienced nurse is better than a computer or a computerized automatic system". In the clinic we often used the observation and opinion of an experienced nurse regarding the diagnostic and prognosis of a patient. And the nurse's answer was often a useful light on the dark road of diagnosis or prognosis.

- $\quad$ On the other hand, a close collaboration must be kept with the patient and correct information of the patient by an appropriate dose of data, adjusted to the condition of the patient. The patient - physician relationship must be reinforced and educated since nowadays has become poor. In the past, patients had more confidence in their physician rather than in medicine, meanwhile today the faith in medicine increases while the faith in the physician decreases ${ }^{3}$ and the physician's responsibility towards the patient increases.

- The medical risk will never be completely eliminated and therefore, our inner restlessness as physicians remains permanent in front of the patient.

\section{REFERENCES}

[1] BELIS V., - Treaty of Forensic Medicine, Ed. Medicala, 1995.

[2] CARONE P., NAGY B., - Medical discipline: dealing with physicians who are: unscrupulous, disabled and incompetent, N.Y, State J. Med., 1979.

[3] CLARKE C. - Can medical practice be free of risk? J. Roy. Soc. Med., 1979.

[4] COCHRANE A. - L'inflation médicale. Réflexions sur l'efficacité de la médicine, Ed. Galilée, Paris. 1977.

[5] DUREGARD H. - Responsabilité médicale et défense des médecins, Med. De France, 1974.

[6] DUTESCU B. - Ethos in medicine, Ed. Medicala, Bucharest, 1979.

[7] LAURY G.V. - Le difficile rôle du médecin. Med. Et Hyg. (Genève), 1982.

[8] Law 288/2008 - Pharmacy Law with subsequent additions,

[9] Law 95/2006 -Reform in the health sector.

[10] MADELIN PH. - Malades et médecins. La crise de confiance. Ed. du Seuil, Paris, 1981. 
[11] OZUN R., POENARU E. - Social and professional responsibility of the physician, Ed. Medicala, Bucharest, 1973.

[12] SCRIPCARU GH., CIORNEA T. - Medical deontology, Ed. Medicala, Bucharest, 1979.

[13] TERBANCEA M., SCRIPCARU GH. - Deontological coordinates of the medical act, Ed. Medicala, Bucharest, 1989 